ẼESTI NSV TEADUSTE AKADËEMIA TOIMETISED. 30. KOIDË

GEOLOOGIA. 1981, NR. 1

ИЗВЕСТИЯ АКАДЕМИИ НАУК ЭСТОНСКОИ ССР. ТОМ 30 ГЕОЛОГИЯ. 1981, № 1

Б. АРЕНЬ, Казимира ЛЕНДЗНОН, Э. ПНРРУС

\title{
ДИАГЕНЕТИЧЕСКИЙ СИДЕРИТ В ОТЛОЖЕНИЯХ НИЖНЕГО КЕМБРИЯ ПОЛЬШИ И СТРАТИГРАФИЧЕСКОЕ ЗНАЧЕНИЕ ЭТОЙ МИНЕРАЛИЗАЦИИ
}

При повторном осмотре керна скв. Мельник Восточной Польши летом 1977 г. авторами в радзинской свите на гл. 1319,0-1334,5 м в виде отдельных находок и выше на гл. 1304,0 и 1265,0 м обнаружены сцементированные участки алевролитов или мелкие линзовидные гнезда в глинах, которые после длительной аэрации керна приобрели характерный светло-коричневый цвет, напоминающий сидерит. По данным химического и рентгеноструктурного анализов, выполненных в Институте геологии АН ЭССР, в этих образованиях действительно идентифицирован сидеритовый цемент в количестве $28-41 \%$ (таблица). Такое проявление небольших количеств железистого карбоната вряд ли заслуживало бы большего внимания, однако нахождение его именно в низах радзинской свиты, сопоставляемой с вергальско-раусвеской частью разреза Прибалтики, в которой установлено седиментационное рудопроявление железа как мощный стратиграфический маркер для данного уровня (Брангулис и др., 1974), вызвало интерес и к железной минерализации в отложениях Восточной Польши.

Действительно, несмотря на свою разобщенность в территориальном и структурном плане, радзинская часть разреза в скв. Мельник очень похожа на разрез его стратиграфического аналога в Прибалтике. Как и в Балтийской синеклизе, так и здесь непосредственно над песчаниками (каплоносская свита; 1504-1352 м) залегает сперва более тонкозернистая часть радзинской свиты $(1352-1318$ м), представленная преимущественно пелитовыми алевролитами и алевритовыми глинами, глинистость которых постепенно уменьшается вверх по разрезу. Этот комплекс и является основным носителем сидеритовых включений. Қак и в Прибалтике, количество глауконита в этом интервале явно подавлено, в то же время встречается много тонких пиритизированных следов жизнедеятельности донных организмов. Выше по разрезу (1318-1272 м) породы замещаются более алевритовыми, содержащими тонкие пленки и примазки глины, по которым четко фиксируется биотурбационная текстура типа «кракстен», аналогичная такой же в верхней половине ирбенской свиты Северной Прибалтики. Сидерит в этой части разреза обнаружен лишь в единичных проявлениях, а количество глауконита в породе становится более заметным, чем в нижележащих глинистых алевролитах. Выше по разрезу $(1272-1264,9$ м) наблюдается комплекс переслаивания темноцветных однородных глин и грубозернистых алевролитов, в которых текстура «кракстен» встречается лишь в отдельных прослоях (аналог низов кибартайской свиты Прибалтики!). В этой части разреза обнаружены единичные линзочки сидерита мощностью всего лишь 1 -2 мм. Еще выше $(1264,9-1247,3$ м) разрез представлен преимущественно песчаными породами, содержа-

1 ENSV TA Toimetised. G 11981 
Химический состав сидеритов нижнего кембрия Северной Прибалтики и Польши

\begin{tabular}{|c|c|c|c|c|c|c|c|}
\hline Скважина & $\begin{array}{c}\text { Глубина, } \\
M\end{array}$ & $\begin{array}{l}\text { Нераст- } \\
\text { вор. } \\
\text { остаток }\end{array}$ & $\mathrm{FeO}$ & $\mathrm{MnO}$ & $\mathrm{MgO}$ & $\mathrm{CaO}$ & $\mathrm{CO}_{2}$ \\
\hline \multicolumn{8}{|c|}{ Северная Прибалтика } \\
\hline $\begin{array}{l}\text { Кандава } 24 \\
\text { Кандава } 26 \\
\text { Талсы }\end{array}$ & $\begin{array}{l}1392,4 \\
1242,2 \\
1241,0 \\
1085,6\end{array}$ & $\begin{array}{r}22,65 \\
22,44 \\
9,24 \\
24,31\end{array}$ & $\begin{array}{l}37,30 \\
42,24 \\
47,29 \\
40,31\end{array}$ & $\begin{array}{l}1,26 \\
1,23 \\
0,39 \\
1,35\end{array}$ & $\begin{array}{l}2,25 \\
2,35 \\
2,35 \\
2,34\end{array}$ & $\begin{array}{l}4,40 \\
1,88 \\
3,28 \\
2,33\end{array}$ & $\begin{array}{l}21,76 \\
24,00 \\
27,01 \\
24,78\end{array}$ \\
\hline \multicolumn{8}{|c|}{ Северная Польша } \\
\hline $\begin{array}{c}\text { Голдап } \\
\text { ", } \\
\text { ", } \\
\text { ", } \\
\text { Бартошице } \\
\text {," }\end{array}$ & $\begin{array}{l}1607,0^{*} \\
1604,0^{*} \\
1603,5^{*} \\
1603,1^{*} \\
1601,0^{* *} \\
1578,6^{*} \\
1578,2 \\
2053,0^{*} \\
2050,0 \\
2049,9\end{array}$ & $\begin{array}{l}67,16 \\
77,91 \\
68,81 \\
22,91 \\
67,81 \\
84,00 \\
79,16 \\
85,48 \\
44,75 \\
37,90\end{array}$ & $\begin{array}{r}6,43 \\
10,18 \\
11,41 \\
25,90 \\
5,07 \\
4,85 \\
8,55 \\
5,05 \\
25,84 \\
30,78\end{array}$ & $\begin{array}{l}0,59 \\
0,23 \\
0,34 \\
3,07 \\
0,79 \\
0,10 \\
0,40 \\
0,08 \\
0,54 \\
0,70\end{array}$ & $\begin{array}{l}2,93 \\
0,97 \\
1,74 \\
3,91 \\
4,01 \\
0,65 \\
1,67 \\
0,94 \\
1,79 \\
1,00\end{array}$ & $\begin{array}{l}3,38 \\
5,30 \\
3,60 \\
9,90 \\
6,43 \\
1,75 \\
0,93 \\
0,56 \\
1,25 \\
1,88\end{array}$ & $\begin{array}{r}13,28 \\
7,61 \\
11,12 \\
26,75 \\
13,15 \\
12,75 \\
7,49 \\
6,55 \\
17,50 \\
20,35\end{array}$ \\
\hline \multicolumn{8}{|c|}{ Восточная Польша } \\
\hline $\begin{array}{c}\text { Мельник } \\
\text { " } \\
\text { " } \\
\text { ", } \\
\text { " } \\
\text {, }\end{array}$ & $\begin{array}{l}1334,5 \\
1333,1 \\
1333,2 \\
1331,6 \\
1327,8 \\
1327,5 \\
1319,5 \\
1265,0\end{array}$ & $\begin{array}{l}73,37 \\
56,73 \\
55,57 \\
60,63 \\
65,14 \\
55,14 \\
49,70 \\
72,00\end{array}$ & $\begin{array}{l}11,65 \\
20,16 \\
21,45 \\
19,78 \\
16,57 \\
22,02 \\
24,54 \\
13,15\end{array}$ & $\begin{array}{l}0,37 \\
0,95 \\
0,86 \\
0,31 \\
0,65 \\
0,75 \\
0,97 \\
0,88\end{array}$ & $\begin{array}{l}1,47 \\
2,47 \\
1,08 \\
1,30 \\
1,04 \\
1,16 \\
2,08 \\
3,40\end{array}$ & $\begin{array}{l}0,61 \\
0,54 \\
1,50 \\
1,80 \\
0,72 \\
0,54 \\
1,62 \\
0,83\end{array}$ & $\begin{array}{r}8,56 \\
17,05 \\
14,11 \\
11,78 \\
12.57 \\
13,92 \\
16.14 \\
8,70\end{array}$ \\
\hline
\end{tabular}

* Смесь сидерита и доломита; ** доломит. Анализы выполнены В. Ткаченко в лаборатории Института геологии АН ЭССР.

щими, как и соответствующие слои в Прибалтике, обильный глауконит, фосфатный детрит брахиопод и многочисленные шаровидные конкреции пирита. Сидерит в этой части разреза не обнаружен.

Таким образом, один из типовых разрезов Восточной Польши скв. Мельник - обнаруживает во многих деталях, включая и проявления диагенетической минерализации железа, большое сходство с разрезами центральных зон Балтийской синеклизы. В то же время существующие палеогеографические представления (Палеогеография ..., 1980) не позволяют рассматривать формирование этих отложений в единых структурно-геологических обстановках. Следовательно, близость геологических особенностей строения этих разрезов отражает прежде всего общие региональные тенденции в раннекембрийском осадконакоплении, а наблюдаемая аномальная минерализация в отношении соединений железа на данном фоне - отклонения в нормально-морской седиментации. Это обстоятельство придает рассматриваемым проявлениям минерализации важное маркирующее значение по отношению ко всему западному региону платформы.

Правда, в пределах Балтийской синеклизы, где данное рудопроявление изучено весьма полно (Апините, 1974; Пиррус, 1977 и др.), сидеритовая минерализация выражена сравнительно слабо. Здесь распространяются главным образом гетитовые оолитовые руды, суммарная мощность слоев которых доходит иногда до $5 \mathrm{M}$. Сидеритовые прояв- 


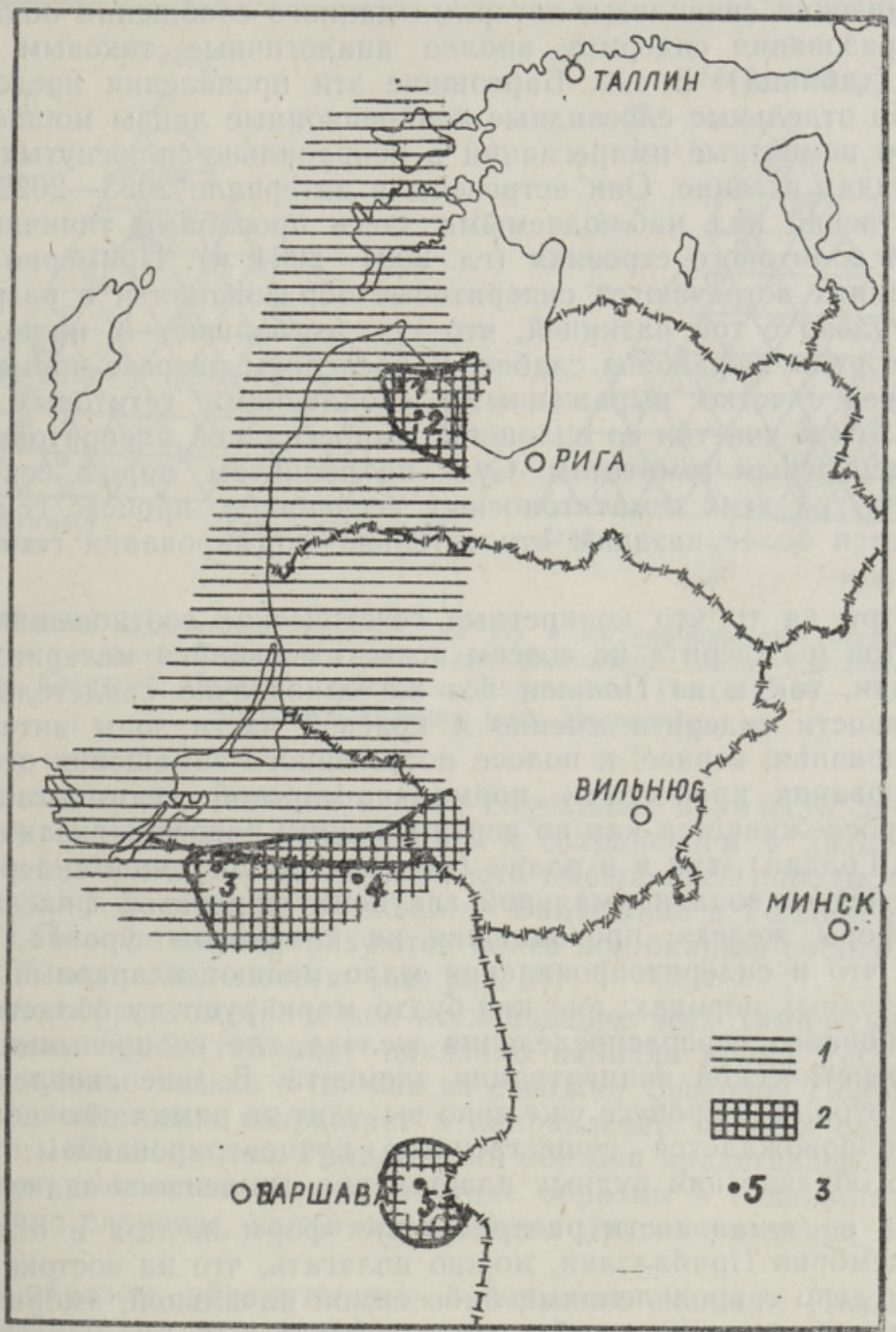

Рис. 1. Расположение сидеритопроявлений на вергальско-раусвеском уровне нижнего кембрия на территории Польши и Прибалтики. 1 - зона распространения гетитовых оолитовых руд, 2 зона пород с сидеритовой минерализацией, 3 - разрезы Талсы (1), Кандава (2), Бартошице (3), Голдап (4), Мельник (5).

ления обнаружены лишь в отдельных разрезах в зоне выклинивания гетитовых руд на юго-западе Литвы и на востоке Курземского полуострова в Латвии (скважины Талсы, Кандава; рис. 1). Обычно эти слоевидные конкреции мощностью 5-15 мм, иногда - раздробленные и переброшенные в брекчиевидные скопления. В отдельных случаях сидерит ассоциируется здесь с хемогенным зеленовато-серым агрегатом шамозита. Нередко в массивной глине наблюдаются и скопления шариковых микроконкреций сидерита диаметром $0,2-1,0$ мм. В некоторых случаях отмечаются сидеритовые ядра в гетитовых оолитах.

Добавочную информацию о роли сидерита в Балтийской синеклизе дало повторное обследование кернов скважин Бартошице и Голдап в Северной Польше. В этих разрезах, располагающихся на юго-восточ- 
ном ограничении синеклизы, авторами данного сообщения обнаружены также образования сидерита, вполне аналогичные таковым из скв. Мельник (таблица). В скв. Бартошице эти проявления представляют собой либо отдельные слоевидные конкреционные линзы мощностью до 1 см, либо цементные импрегнации в неправильно-сплюснутых алевритовых гнездах в глине. Они встречены в интервале 2053-2029 м, т. е. непосредственно над наблюдаемыми здесь прослоями типичных гетитовых руд оолитового строения (гл. 2094-2064 м). Примерно в таких же сочетаниях встречаются сидеритовые образования и в разрезе скв. Голдап, только с той разницей, что тут их больше, а нижележащие оолитовые руды выражены слабее. В последнем разрезе кроме отдельных уровней с четко выраженными скоплениями гетитовых оолитов наблюдаются и участки со сплошной импрегнацией алевритовых пород с тонкодисперсным гематитом. Судя по реликтам пород сероцветной окраски внутри этих гематитоносных песчаников, процесс гематитизации является более поздним относительно формирования гетита и сидерита.

Несмотря на то что конкретные генетические соотношения гетитовых оолитов и сидерита не совсем ясны, имеющийся материал как из Прибалтики, так и из Польши все же однозначно свидетельствует о приуроченности сидерита именно к краевой части зоны интенсивного рудообразования, вернее, к полосе постепенного замещения осадочного рудообразования процессами нормально-морской седиментации. Это хорошо прослеживается как по вертикальному разрезу (скважины Бартошице и Голдап), так и в плане (см. рис. 1). За зоной сидеритообразования следует зона нормальной глауконит-пиритовой фиксации подвижных форм железа, проходившая на кларковом уровне. Следует отметить, что и сидеритопроявления мало меняют кларковый фон железа в исходных породах: они как-будто маркируют ту область постседиментационного перераспределения железа, где не превышается уровень диагенетической концентрации элемента. В зоне скопления гетитовых оолитов этот процесс уже явно выходит за рамки обычного диагенеза и сопровождается существенным концентрированием элемента вплоть до образования рудных пластов промышленного значения.

Исходя из зональности распределения форм железа в отложениях раннего кембрия Прибалтики, можно полагать, что на востоке Польши мы имеем дело с проявлениями либо самой начальной, эмбриональной стадии рудообразования, либо аналоги гетитовых руд Прибалтики в дальнейшем можно находить и в других разрезах этого района. Основание для последнего предположения дают находки гетитовых оолитовых руд около 200 км юго-восточнее в разрезе скв. ВладимираВолынской на Украине (Стратиграфия верхнедокембрийских ..., 1979; c. 164). В более южных скважинах на территории Восточной Польши как гетитовые оолиты, так и сидеритовые образования пока не обнаружены. Специально в этих целях был повторно просмотрен разрез скв. Качлоносцы.

Химический состав сидеритов, обнаруженных в разрезах скважин Польши, весьма изменчив (таблица; рис. 2). Характерным для них является большое количество силикатного составляющего, несущественная роль в составе карбонатного компонента $\mathrm{MnCO}_{3}$ и весьма меняющиеся количества $\mathrm{MgCO}_{3}$ и $\mathrm{CaCO}_{3}$, достигающие иногда $48 \%$ всей карбонатной составляющей конкреции. Эти особенности отличают данные сидериты от сидеритов Северной Прибалтики, в которых резко превалирует $\mathrm{FeCO}_{3}$. Надо полагать, что образование сидеритов в Польше протекало в менее выдержанных условиях диагенеза и поэтому 


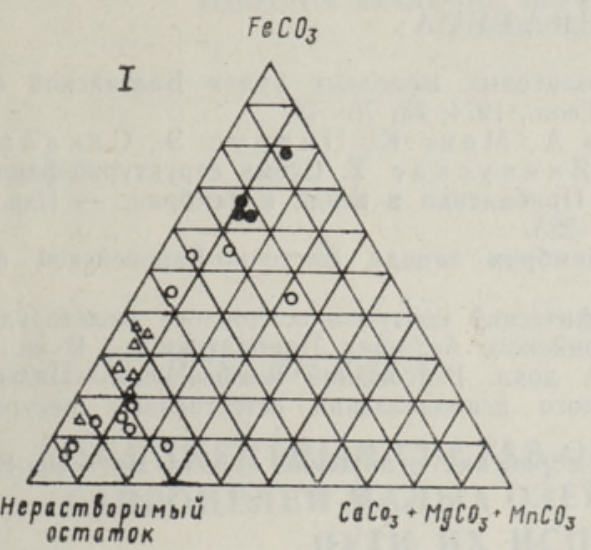

Pис. 2. Состав сидеритовых образований (I) и их карбонатной составляющей (II). 1 - сидериты Северной Прибалтики (скважины Талсы, Қандава), 2 сидериты Северной Польши (скважнны Бартошице, Голдап), 3 - сидериты Восточной Польши (скв. Мельник).

сопровождалось связыванием весьма случайных количеств добавочных катионов в сидеритовые образования и сохранением в них также существенного объема силикатного скелета вмещающей породы. Особенно это относится к сидеритам из скважин Бартошице и Голдап. Сидериты Восточной Польши характеризуются более постоянным составом и специфической магнезиальностью (см. рис. 2).

Рентгенодифрактометрическое исследование всех химически проанализированных проб (таблица) показало наличие кроме $\mathrm{FeCO}_{3}$ еще и доломита, однако только в пробах из скважин Северной Польши. Роль доломита в последних возрастает в направлении нижних слоев разрезов. На гл. $1601,0 \mu$ в скв. Голдап один образец представлен полностью железистым доломитом. Самые верхние образцы в скважинах Голдап и Бартошице сложены, как и образования других разрезов, одним сидеритом.

Таким образом, обнаруженные в разрезах скважин Польши сидеритопроявления, располагающиеся на одном стратиграфическом уровне с бурыми оолитовыми рудами Балтийской синеклизы, не могут быть рассмотрены как явления случайные. Наоборот, они расширяют маркирующее значение следов минерализации железа на более обширную территорию и имеют поэтому важное значение для стратификации кембрийских толщ. Учитывая склонность образования как сидерита, так и гетитовых оолитов в несколько опресненных относительно нормально-морских обстановках седиментации - в условиях подавленной фиксации железа глауконитом и пиритом, надо полагать, что очень развернутая по площади минерализация отражает важные региональные события в бассейнах западного обрамления платформы. Возможно, что на данном этапе по каким-то причинам был нарушен нормальный водообмен краевых морей с океаном, вследствие чего влияние стока пресных вод с окружающего материка с выдержанным гумидным климатом дошло до зоны накопления алевритово-пелитовых осадков, вызывая в них отклонения в протекании нормально-морского диагенеза. В этом случае рассматриваемый уровень приобретает значимость важного временного репера. Так или иначе, данная проблема требует дальнейшего систематического изучения, а соответствующие минералопроявления - тщательной документации, 
Апините И. О нижнекембрийских оолитовых железных рудах Балтийской синеклизы. - Изв. АН ЭССР. Хим. Геол., 1974, 23, 76-79.

Брангулис А., Кала Э., М ардла А., Менс К., Пир рус Э., Сакалауск а с B., Фрид рих соне А., Я н к ускас Т. Схема структурно-фациального районирования территории Прибалтики в венде и кембрии. - Изв. АН ЭССР. Хим. Геол., $1974,23,218-225$.

Палеогеография и литология венда и кембрия запада Восточно-Европейской платформы. М., 1980.

Пи р р у с Э. А. Фациально-палеогеографический контроль осадочного железорудного процесса на примере раннекембрийского бассейна Прибалтики. - $\mathrm{B}$ кн.: Региональная палеогеография. Тез. докл. Всесоюзной конференции «Палеогеографические основы рационального использования естественных ресурсов». Киев, 1977, 212-214.

Стратиграфия верхнедокембрийских и кембрийских отложений запада Восточно-Европейской платформы. М., 1979.

Геологический институт, Вариава

Институт геологии

Академии наук Эстонской ССР

Поступила в редакцию $10 /$ IV 1980

\section{B. AREN, Kazimiera LENDZION, E. PIRRUS}

\section{DIAGENEETILINE SIDERIIT POOLA ALAMKAMRBIUMIS JA SELLE MINERALISATSIOONI STRATIGRAAFILISEST TÄHTSUSEST}

Ida-Poola Melniku ning Pōhja-Poola Goldapi ja Bartoszyce puursüdamikest leitud sideriidiilmingud, mis paiknevad samal stratigraafilisel tasemel Balti sünekliisi keskosas levivate götiit-ooliitsete maagikihtidega, viitavad nimetatud mineralisatsiooninähete ulatuslikule regionaalsele levikule ja vöimaldavad neid kasutada olulise stratigraafilise markerina. Konkretsioonilised sideriidiilmingud paiknevad götiitsete maakide väljakiildumise alal, harvemini isoleeritud laikudena (joon. 1). Nähtavasti on nii götiidi kui ka sideriidi moodustumise pōhjuseks olnud suhteliselt lühiajaline kõrvalekaldumine varakambriumi normaalmerelisest settimisrežiimist, arvatavasti vete magestumise suunas, millele viitab nende mineraalide negatiivne korrelatsioon glaukoniidiilmingutega.

Poola alalt leitud sideriidid sisaldavad palju ümbriskivimi silikaatset lisandit ning karbonaatses komponendis peale raua ka rohkesti kaltsiumi ja magneesiumi (tab., joon. 2): Röntgenanalüüsi pōhjal otsustades on siiski valdav sideriit, millele Pōhja-Poola läbilōikeis lisandub ka rauarikas dolomiit. Baltikumist (Lääne-Lätist) pärinevad ilmingud on silikaatse lisandi poolest vaesemad ning väljapeetult sideriitse koostisega.

\section{B. AREN, Kazimiera LENDZION, E. PIRRUS}

\section{DIAGENETIC SIDERITE IN LOWER CAMBRIAN SEDIMENTARY ROCKS OF POLAND AND ITS STRATIGRAPHICAL SIGNIFICANCE}

In the Melnik core of East-Poland and in the Goldap and Bartoszyce cores of NorthPoland an occurrence of siderite has been established. Stratigraphically these deposits are situated at the same level as the oolitic goethite-bearing strata in the Cambrian sequence of the Baltic syneclise. This fact testifies to the regional nature of this phenomenon and makes it possible to use it as a stratigraphic marker.

The siderite occurs mostly in connection with the thinning out of the goethite mineralization and seldom as isolated spots (Fig. 1).

It seems that the precipitation of goethite and siderite probably depends on the short-time inclination of the hydrochemical regime from normal marine conditions on the increasing inflow of freshwater in the Early Cambrian, which is also proved by the negative correlation of goethite-siderite with glauconite.

As to the chemical composition of the siderites found in Poland, they contain a considerable admixture of silicates from the surrounding rocks accompanied by a high content of $\mathrm{Ca}$ and $\mathrm{Mg}$ besides $\mathrm{Fe}$ (Table, Fig. 2) in the carbonate part. According to the results of X-ray determination, after all, the siderite is prevailing, which, in North-Poland, is accompanied by dolomite rich in iron. Unlike the siderites of Poland the northern Baltic șiderites are purer and contain a lesser amount of silicate admixture, 